Article

\title{
Separating Electronic from Steric Effects in Ethene/ $\alpha$-Olefin Copolymerization: A Case Study on Octahedral [ONNO] Zr-Catalysts
}

\author{
Francesco Zaccaria ${ }^{1,2}{ }^{\mathbb{D}}$, Roberta Cipullo ${ }^{1} \mathbb{(}$, Andrea Correa ${ }^{1}$, Peter H. M. Budzelaar ${ }^{1}{ }^{(}$, \\ Vincenzo Busico ${ }^{1}$ and Christian Ehm ${ }^{1, *(D)}$ \\ 1 Dipartimento di Scienze Chimiche, Università di Napoli Federico II, Via Cintia, 80126 Napoli, Italy; \\ francesco.zaccaria@unipg.it (F.Z.); rcipullo@unina.it (R.C.); andrea.correa@unina.it (A.C.); \\ p.budzelaar@unina.it (P.H.M.B.); busico@unina.it (V.B.) \\ 2 Dipartimento di Chimica, Biologia e Biotecnologie and CIRCC, Università di Perugia, Via Elce di Sotto 8, \\ 06123 Perugia, Italy \\ * Correspondence: christian.ehm@unina.it
}

Received: 30 May 2019; Accepted: 17 June 2019; Published: 20 June 2019

\begin{abstract}
Four $\mathrm{Cl} / \mathrm{Me}$ substituted [ONNO] $\mathrm{Zr}$-catalysts have been tested in ethene/ $\alpha$-olefin polymerization. Replacing electron-donating methyl with isosteric but electron-withdrawing chlorine substituents results in a significant increase of comonomer incorporation. Exploration of steric and electronic properties of the ancillary ligand by DFT confirm that relative reactivity ratios are mainly determined by the electrophilicity of the metal center. Furthermore, quantitative DFT modeling of propagation barriers that determine polymerization kinetics reveals that electronic effects observed in these catalysts affect relative barriers for insertion and a capture-like transition state (TS).
\end{abstract}

Keywords: olefin copolymerization; reactivity ratios; electronic effects; salan catalysts; post-metallocene; DFT; insertion kinetics; olefin capture

\section{Introduction}

The production of ethene/ $\alpha$-olefin copolymers is one of the largest-scale processes of the chemical industry [1,2]. Linear low density polyethylene (LLDPE), obtained by the copolymerization of ethene with $\alpha$-olefins like 1-butene, 1-hexene, or 1-octene, is one of the most representative examples of this class of copolymers, finding broad applications in the packaging industry [3].

The incorporation of $\alpha$-olefins in a linear polyethylene backbone leads to chain branching, which can dramatically affect polymer crystallization and, subsequently, mechanical and rheological material properties [4-6]. Comonomer content and distribution within the polymer chain are consequently two critical microstructural parameters affecting macroscopic properties of ethene/ $\alpha$-olefin copolymers. The design of catalysts that allow polymer microstructure fine-tuning is therefore especially desirable in this context. Well-defined single-center molecular catalysts based on group IV metallocene and 'post-metallocene' complexes are nowadays often preferred for this kind of copolymerization rather than homologous multi-center, heterogeneous Ziegler-Natta systems [7-9].

Tailoring catalyst properties by ancillary ligand design has been widely exploited to access polymeric materials with desired structural features. Computational chemistry has contributed significantly to the identification of some rationale in the relationships between catalyst structure and properties [10-12]. The demystification of the origins of stereoselectivity is generally considered as a successful example of rational understanding [13-16], although some aspects are still debated [17-22]. Conversely, other catalyst properties, including comonomer affinity, are far less understood. 
Typically, the probability of a comonomer to insert in the $\mathrm{M}-\mathrm{P}$ bond $(\mathrm{M}=$ metal, $\mathrm{P}=$ polymeryl) depends on the last inserted monomeric unit [23]. In such cases, the tendency of a given catalyst to incorporate ethene or an $\alpha$-olefin in the growing polymeryl can be described by first-order Markov statistics, employing two simple parameters denoted as $r_{E}$ and $r_{C}$ [24-26]:

$$
r_{\mathrm{E}}=\frac{k_{\mathrm{EE}}}{k_{\mathrm{EC}}} \quad r_{\mathrm{C}}=\frac{k_{\mathrm{CC}}}{k_{\mathrm{CE}}}
$$

where $k$ is the kinetic constant of the specific propagation reaction indicated by the two subscripts; the first subscript denotes the last inserted monomer, while the second indicates the inserting one. For instance, $k_{\mathrm{EC}}$ refers to the insertion of the comonomer (C) after ethene (E). Under the assumption that the Curtin-Hammett principle applies, reactivity ratios can be expressed in terms of Gibbs free energy differences $\left(\Delta \Delta G^{\ddagger}\right)$ between different propagation barrier heights:

$$
r_{\mathrm{E}}=\frac{k_{\mathrm{EE}}}{k_{\mathrm{EC}}}=e^{\frac{\Delta G_{\mathrm{EC}}^{\ddagger}-\Delta G_{\mathrm{EE}}^{\ddagger}}{\mathrm{RT}}}=e^{\frac{\Delta \Delta G_{(\mathrm{EC}-\mathrm{EE})}^{\ddagger}}{\mathrm{RT}}} ; r_{\mathrm{C}}=\frac{k_{\mathrm{CC}}}{k_{\mathrm{CE}}}=e^{\frac{\Delta G_{\mathrm{CE}}^{\ddagger}-\Delta G_{\mathrm{CC}}^{\ddagger}}{R T}}=e^{\frac{\Delta \Delta G_{(\mathrm{CE}-\mathrm{CC})}^{\ddagger}}{R T}} .
$$

Early polymerization studies have proposed that open coordination geometries might favor coordination and insertion of relatively bulky $\alpha$-olefins, but this assertion has been challenged [27-30]. While it is generally accepted that electronic effects influence comonomer affinity, no definitive consensus has been reached; electron-withdrawing substituents reportedly lead to higher comonomer contents [31-33], but the opposite has also been observed [8,34]. Uncoupling electronic from steric effects when exploring variations of the ancillary ligands is non-trivial $[31,35,36]$; furthermore, pronounced electronic effects generally rely on heteroatom (e.g., F, N, O) containing substituents that might interact or even react with the other components of the catalytic pool (e.g., Al-based cocatalysts), leading to in situ catalyst modifications.

Computational analysis of copolymerization mechanisms is challenging [37,38]. Only very recently, an effective DFT protocol for highly accurate predictions of reactivity ratios has been reported, providing excellent mean average deviations (MAD) from experimental $\Delta \Delta G^{\ddagger}$ of only $0.2-0.3 \mathrm{kcal} / \mathrm{mol}[33,39]$. Exploration of reaction pathways revealed the existence of a 'capture-like' transition state (TS) along the olefin approach vector, which can compete with insertion for the rate-limiting step in chain propagation especially for catalysts having additional steric bulk remote from the active pocket [39]. Furthermore, entropic effects were shown to contribute to the good incorporation capability of constrained geometry catalysts (CGC) [33].

To gain deeper insights into the still ill-understood electronic effects determining comonomer affinities, ancillary ligands with comparable steric hindrance but appreciable electronic differences are needed. The four diamine-bis(phenolate) $\mathrm{Zr}$ catalysts (from here on catalysts $\mathbf{R}_{\mathbf{1}} \mathbf{R}_{\mathbf{2}}, \mathrm{R}=\mathrm{Me}$ or $\mathrm{Cl}$ ) shown in Figure 1 might fulfill these requirements and were therefore selected for a case study. Chlorine and methyl substituents are relatively small, virtually isosteric, but differ in electronic properties-electron-withdrawing $(\mathrm{Cl})$ vs. electron-donating $(\mathrm{Me})$. Furthermore, this class of [ONNO]-type complexes has been widely exploited for mechanistic and kinetic studies due to (1) the ease of modification of ortho- and para-substituents of the phenolate ligands, allowing effective electronic and steric tuning, and (2) the typical controlled kinetic regimes exhibited by these systems in olefin homo- and co-polymerization [40-51]. Thus, in this work, the reactivity ratios for catalysts $\mathbf{R}_{\mathbf{1}} \mathbf{R}_{\mathbf{2}}$ have been experimentally determined in the copolymerization of ethene with $\alpha$-olefins, i.e., 1-butene (B) and propene (P). DFT modeling, using the aforementioned optimized protocols [33,39], provides a plausible interpretation for the dependence of reactivity ratios on the substitution pattern of the [ONNO] ligands. 


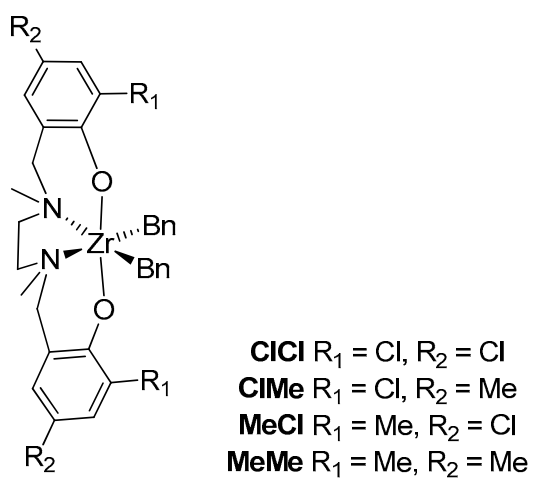

Figure 1. Diamine-bis(phenolate) Zr-complexes $\mathbf{R}_{\mathbf{1}} \mathbf{R}_{\mathbf{2}}(\mathrm{Bn}=$ benzyl).

\section{Materials and Methods}

\subsection{Polymerization Experiments}

All manipulations were performed under an inert atmosphere of argon or nitrogen, employing Schlenk line techniques or MBRAUN LABmaster 130 gloveboxes. Precatalysts were synthesized according to previously established procedures [44,48]. Methanol, hydrochloric acid, and di-tert-butylphenol (TBP) were purchased from Sigma-Aldrich and used as received. All other solvents were purchased from Romil and purified by passing through a mixed-bed activated-Cu/4 $\mathrm{A}$ molecular sieves column in an MBRAUN SPS- 5 unit (final concentration of $\mathrm{O}_{2}$ and $\mathrm{H}_{2} \mathrm{O}<1 \mathrm{ppm}$ ). Ethene and propene were purchased from Rivoira and purified by passing through a mixed-bed activated-Cu/4 $\AA$ molecular sieves column. Methylalumoxane (MAO) was purchased from Chemtura. All glassware was dried in an oven at $150{ }^{\circ} \mathrm{C}$ for at least $16 \mathrm{~h}$ prior to use.

Ethene/propene polymerization experiments were performed as reported in [26]. Ethene/1-butene polymerization experiments were performed using a $300 \mathrm{~mL}$ magnetically stirred jacketed Pyrex reactor with three necks-one with a $15 \mathrm{~mm}$ SVL cap housing a silicone rubber septum, another with a $30 \mathrm{~mm}$ SVL cap, and the last with a two-way Rotaflo tap connected to a Schlenk line, and the ethene and 1-butene cylinders. A solution of activator/scavenger was prepared in the reactor by adding TBP $(1.6 \mathrm{~g})$ to a solution of MAO $(5 \mathrm{~mL},[\mathrm{Al}]=1.6 \mathrm{M})$ in dry toluene $(150 \mathrm{~mL})$ and gently stirring at room temperature for $1 \mathrm{~h}$ to ensure complete scavenging of "free" trimethylaluminum in MAO by TBP $[52,53]$. The reactor was thermostated at $25^{\circ} \mathrm{C}$, evacuated to remove argon, and then saturated with 1-butene (1.1 bar) and subsequently with ethene ( 0.55 or 1.1 bar; see Table S1). Ethene was fed in continuum at a constant operating pressure. Saturation was monitored by gas chromatography (GC) until the gas-liquid equilibrium was established. Concentrations of monomers in the liquid phase were determined using the equations of Kissin [54]. The polymerization was started by injecting a solution of precatalyst in toluene $(<1 \mathrm{~mL})$ through the silicone rubber septum with a syringe. The reaction was then stopped by turning off the ethene supply, venting the reactor, and rapidly quenching with a $95 / 5 \mathrm{v} / \mathrm{v}$ methanol/ $\mathrm{HCl}$ (aqueous, concentrated) solution. The resulting polymer was coagulated with $400 \mathrm{~mL}$ of the same acidic solution, decanted, and vacuum-dried at $50^{\circ} \mathrm{C}$ for $16 \mathrm{~h}$. The reaction time was chosen to guarantee a low 1-butene conversion $(<10 \%)$, based on GC analysis of the gas phase.

Polymer samples were characterized by nuclear magnetic resonance (NMR) spectroscopy, using a Bruker AVANCE spectrometer $\left(400 \mathrm{MHz}\right.$ for $\left.{ }^{1} \mathrm{H}\right)$ equipped with a $5 \mathrm{~mm}$ high-temperature cryoprobe on $50 \mathrm{mg} \mathrm{mL}^{-1}$ solutions in tetrachloroethane-1,2- $d_{2}$ at $120^{\circ} \mathrm{C}$. Specific parameters for the measurements were as follows: ${ }^{1} \mathrm{H}$ NMR, $90^{\circ}$ pulse, $2 \mathrm{~s}$ acquisition time, $10 \mathrm{~s}$ relaxation delay, 16 transients, $8.0 \mathrm{kHz}$ spectral width, $32 \mathrm{~K}$ time domain data points; ${ }^{13} \mathrm{C}$ NMR, $45^{\circ}$ pulse, $2.3 \mathrm{~s}$ acquisition time, $5.0 \mathrm{~s}$ relaxation delay, $1 \mathrm{~K}$ transient, $14 \mathrm{kHz}$ spectral width, $64 \mathrm{~K}$ time domain data points. Experimental triad distributions have been determined according to the Randall method [25]. Values of reactivity ratio were calculated according to [55] from the conditional probabilities obtained from best-fit calculations 
of sequence distributions, performed with the Copolstat program (Professor M. Vacatello, University of Naples).

\subsection{DFT Calculations}

Following the protocol described in [56], all geometries were fully optimized using the Gaussian 09 software package [57] in combination with the OPTIMIZE routine of Baker [58,59] and the BOpt software package [60]. Zr- $n \mathrm{Pr}$ and $\mathrm{Zr}$ - $i \mathrm{Bu}$ groups have been used to mimic the $\mathrm{Zr}$-polymeryl species after ethene and propene insertion, respectively. The naked cation approximation has been used [38]. All relevant minima and transition states were fully optimized at the TPSSTPSS level [61] of theory employing correlation-consistent polarized valence double- $\zeta$ Dunning (DZ) basis sets (cc-pVDZ quality) [62] from the EMSL basis set exchange library [63]. The density fitting approximation was used at the optimization stage (resolution of identity, RI) [64-67]. All calculations were performed with Scf $=$ Tight and Int(Grid = Ultrafine) quality settings. All structures represent either true minima (as indicated by the absence of imaginary frequencies) or transition states (with exactly one imaginary frequency corresponding to the reaction coordinate). Convergence criteria were not loosened with the exception of propene BBRA with $\mathrm{Zr}-n \mathrm{Pr}$ cationic species for MeMe (gradient tolerance 0.00015 instead of 0.00010). This approximation should not cause significant error, as all BBRA TSs are located on a plateau of the potential energy surface $[39,68]$. Final single-point energies and natural bond orbital (NBO) [69] analyses were calculated at the M06-2X level of theory [70] employing triple- $\zeta$ Dunning (TZ) basis sets (cc-pVTZ quality) [62]. Enthalpies and Gibbs free energies were then obtained from TZ single-point energies and thermal corrections from the TPSSTPSS/cc-pVDZ-(PP) vibrational analyses; entropy corrections were scaled by a factor of 0.67 to account for decreased entropy in the condensed phase $[33,39,71]$.

\section{Results and Discussion}

\subsection{Ethene/1-Butene Copolymerization}

Catalysts $\mathbf{R}_{\mathbf{1}} \mathbf{R}_{\mathbf{2}}$ were tested in the copolymerization of ethene and 1-butene at $25^{\circ} \mathrm{C}$ and the results are summarized in Table 1 . Catalyst performance is significantly influenced by the substitution pattern of the phenolate rings. In particular, replacing Me with $\mathrm{Cl}$ leads to a higher comonomer incorporation ([B] $\left.]_{\mathrm{cop}}\right)$. Catalyst affinity towards 1-butene increases from $\mathrm{MeMe}$ to $\mathbf{C l C l} ; r_{\mathrm{E}}$ decreases and $r_{\mathrm{B}}$ increases, as shown in Figure 2. Reactivity ratios for $\mathbf{M e C l}$ and $\mathrm{ClMe}$ are very similar but the former exhibits a somewhat higher comonomer affinity. This suggests that the effect of $\mathrm{Cl}$ vs. Me substitution on comonomer affinity depends weakly on the exact position. Interestingly, despite the evident change of the individual $r_{\mathrm{x}}$ parameters, the $r_{\mathrm{E}} r_{\mathrm{B}}$ ratio is very similar for all four catalysts, as shown in Table 1 , and close to unity, indicative of a random comonomer distribution in the polymer chain [23].

Table 1. Experimental results for catalysts $\mathbf{R}_{\mathbf{1}} \mathbf{R}_{\mathbf{2}}$ in ethene/1-butene (E/B) copolymerization.

\begin{tabular}{|c|c|c|c|c|c|c|c|c|c|}
\hline Entry & Catalyst & $R_{\mathrm{p}}{ }^{(\mathrm{a})}$ & $\begin{array}{c}{[\mathrm{B}]_{\mathrm{cop}}{ }^{(\mathrm{b})}} \\
\mathrm{mol} \%\end{array}$ & $\begin{array}{l}P_{n} \text { (c) } \\
\times 10^{-2}\end{array}$ & $r_{\mathrm{E}}{ }^{(\mathrm{d})}$ & 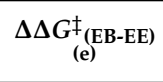 & $r_{B}{ }^{(d)}$ & $\Delta \Delta G_{(\mathrm{e})}^{\ddagger}(\mathrm{BE}-\mathrm{BB})$ & $r_{\mathrm{E}} r_{\mathrm{B}}$ \\
\hline 1 & MeMe & 1 & 24 & 1.00 & $60(1)$ & 2.4 & $0.012(1)$ & -2.6 & 0.7 \\
\hline 2 & $\mathrm{MeCl}$ & 7 & 32 & 0.53 & $38(4)$ & 2.2 & $0.025(4)$ & -2.2 & 1.0 \\
\hline 3 & ClMe & 31 & 37 & 0.24 & $33(1)$ & 2.1 & $0.034(4)$ & -2.0 & 1.1 \\
\hline 4 & $\mathrm{ClCl}$ & 360 & 43 & 0.22 & $22(1)$ & 1.8 & $0.06(2)$ & -1.7 & 1.3 \\
\hline
\end{tabular}

In toluene $(150 \mathrm{~mL}) ; 25^{\circ} \mathrm{C} ; p(\mathrm{~B})=p(\mathrm{E})=1.1$ bar; cocatalyst $=\mathrm{MAO} / \mathrm{TBP}\left([\mathrm{Al}]=5.4 \times 10^{-2} \mathrm{M}\right)$. $\mathrm{E}=$ ethene; $\mathrm{B}=1$-butene. (a) Productivity in $\mathrm{kg}$ (copolymer) $\cdot \mathrm{mol}(\mathrm{Zr})^{-1} \cdot\left[\mathrm{C}_{\mathrm{n}} \mathrm{H}_{2 \mathrm{n}}\right]^{-1} \cdot \mathrm{h}^{-1}$; (b) 1-butene content in the copolymer, determined by ${ }^{13} \mathrm{C}$ $\mathrm{NMR}$; (c) average copolymerization degree determined by ${ }^{1} \mathrm{H}$ NMR based on the concentration of chain end groups; (d) average values obtained from two experiments at different $p(\mathrm{E})$ ( 0.5 and 1.1 bar, see Supporting Information);

(e) calculated from experimental $r$ values, according to Equation (2).

Steric effects in the present catalyst class are mainly related to the ortho-substituents on the phenolate rings, due to their proximity to the metal center [41]. The $\mathrm{Cl}$ and Me substituents considered 
here are small and isosteric and, in $\alpha$-olefin homopolymerization, catalysts $\mathrm{ClCl}$ and MeMe exhibit nearly identical, low stereoselectivity [48]. Differences in catalytic performance can therefore be ascribed mainly to electronic effects, resulting from $\mathrm{Cl} / \mathrm{Me}$ exchange (vide infra).

The marked increase in comonomer affinity is accompanied by an appreciable increase of productivity $\left(R_{\mathrm{p}}\right)$ and a decrease of the average copolymerization degree $\left(P_{\mathrm{n}}\right)$. Trends in activity are generally difficult to rationalize, since they strongly depend not only on intrinsic barriers for chain propagation, but also on the percentage of active $\mathrm{Zr}$-centers and catalyst decay mechanisms [10,72]. The amount of active metal is often relatively small [73,74], and difficult to determine [75]. Nevertheless, results in Table 1 are in line with general observation that the reactivity of cationic complexes increases with the electrophilicity of the metal center (vide infra) [76], although this can be affected by ion pairing effects in solution $[77,78]$. Concerning the average $P_{n}$, the unsaturated chain ends observed by polymer microstructural analysis indicate a dominant termination pathway by $\beta-\mathrm{H}$ transfer routes; the negligible dependence of $P_{\mathrm{n}}$ on ethene pressure (see Supporting Information) points to $\beta-\mathrm{H}$ transfer to the monomer being favored over $\beta-\mathrm{H}$ transfer to the metal center [79].

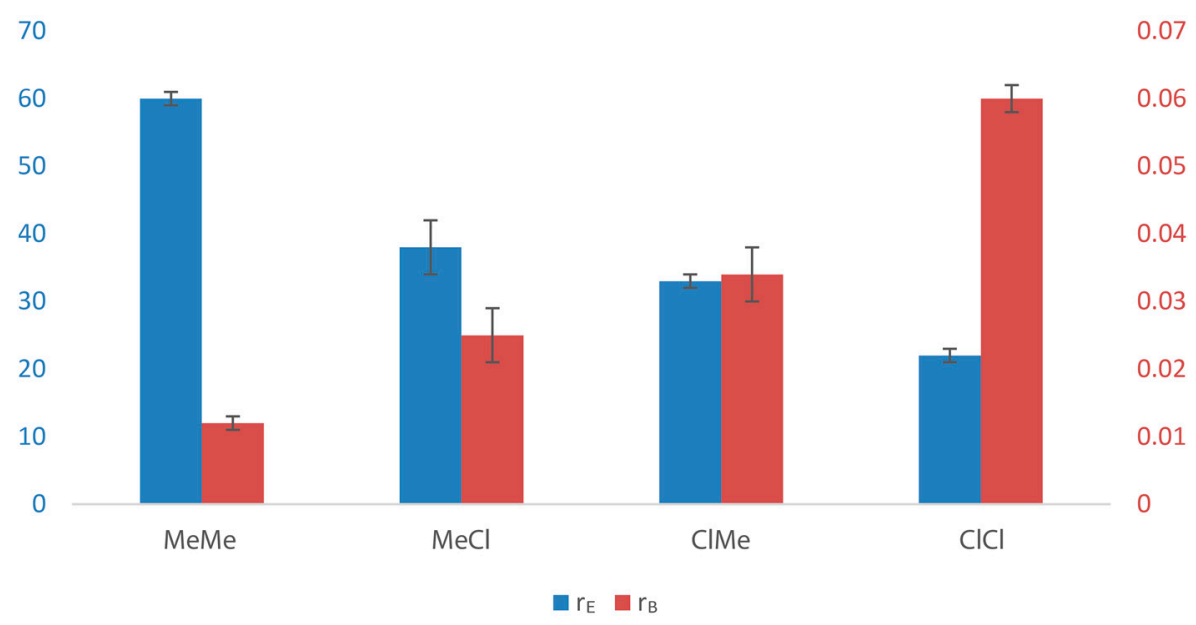

Figure 2. Trends in $r_{\mathrm{E}}$ and $r_{\mathrm{B}}$ for catalysts $\mathbf{R}_{\mathbf{1}} \mathbf{R}_{\mathbf{2}}$ (see Table 1).

\subsection{Computational Modeling}

To unravel the connection between the catalyst structure and comonomer affinity, DFT studies have been carried out on complexes $\mathbf{R}_{\mathbf{1}} \mathbf{R}_{\mathbf{2}}$. The computational protocol (see Materials and Methods for details) has been previously benchmarked for group IV precatalysts and TSs relevant to olefin polymerization [54,74,80-82], including specifically those for predicting reactivity ratios in copolymerization [33,39]. A facfac geometry for all complexes and TSs has been considered, which is generally accepted to be the most stable for the neutral complexes and the cationic active species; interconversion between active facfac and inactive mermer configurations of the naked cationic complex is generally assumed to represent a rapid pre-equilibrium with respect to chain propagation $[43-45,83]$.

\subsubsection{Connection between Electronic/Steric Properties of $\mathbf{R}_{\mathbf{1}} \mathbf{R}_{\mathbf{2}}$ and E/B} Copolymerization Performance

As the optimization of TSs for chain propagation is not always straightforward (vide infra), a more detailed analysis of the relationship between reactivity ratios and catalyst structure has been initially carried out by considering the neutral precatalysts and two suitable computational parameters to describe the electronic and steric properties of the ancillary ligands. To avoid complications due to the conformational rearrangements of the Zr-benzyl groups, the dichloride analogues of $\mathbf{R}_{\mathbf{1}} \mathbf{R}_{\mathbf{2}}$ have been used. Electronic changes of the [ONNO] ligands were estimated by looking at the natural population analysis (NPA) charges of the $\mathrm{ZrCl}_{2}$ fragments, hereinafter denoted as $q_{\mathrm{ZrCl}}$. Higher charges are indicative of more electrophilic metal centers and, therefore, of less electron-donating ligands. Indeed, 
$q_{\mathrm{ZrCl2}}$ increases progressively with the degree of chlorination of the [ONNO]-ligand, going from MeMe to $\mathbf{C l C l}$, as expected based on the more electron-withdrawing nature of $\mathrm{Cl}$, as shown in Table S6. Figure 3 shows that the experimental $\Delta \Delta G^{\ddagger}$ for $r_{\mathrm{E}}$ and $r_{\mathrm{B}}$ correlate well with $q_{\mathrm{ZrCl} 2}$ for this catalyst set $\left(\mathrm{R}^{2} \geq 0.93\right.$ for linear fitting; see also Table S6). Interestingly, the minor difference in comonomer affinity of $\mathbf{M e C l}$ and $\mathrm{ClMe}$ is nicely reproduced. Accordingly, ortho-substituent influence on the phenolate ring dominates over para-position also from an electronic point of view, in line, for instance, with the higher acidity of $o$-chlorophenol ( $\left.\mathrm{p} K_{\mathrm{a}} \approx 8.6\right)$ with respect to $p$-chlorophenol $\left(\mathrm{p} K_{\mathrm{a}} \approx 9.4\right)$ [84]. The difference in electronic effects imparted by ortho- and para-substituents is however usually overshadowed by steric differences [41].

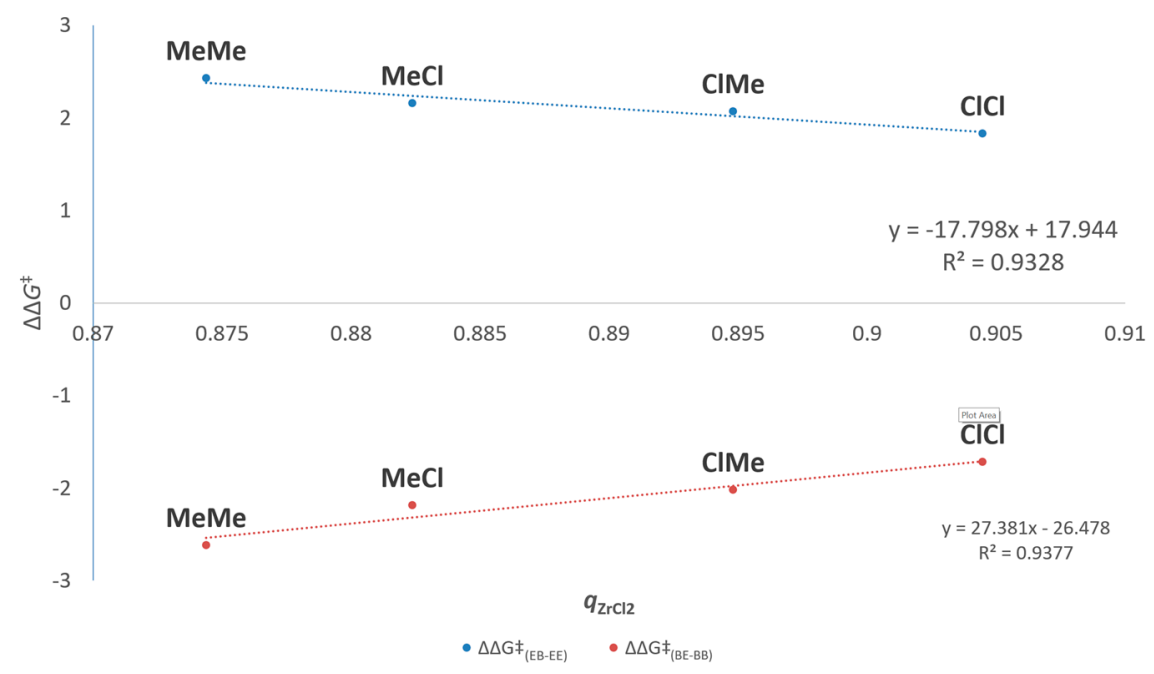

Figure 3. Correlation between $\Delta \Delta G^{\ddagger}$ corresponding to the $r$-parameters for ethene/1-butene copolymerization and $\boldsymbol{q}_{\mathrm{ZrCl} 2}$ for catalysts $\mathbf{R}_{\mathbf{1}} \mathbf{R}_{\mathbf{2}}$ (see also Table S6).

To describe the steric hindrance imparted by the ancillary ligand framework, the percentage buried volume in the catalyst active pocket (\% $V_{\text {bur }}$, see also Supporting Information) can be used, as proposed by Cavallo and coworkers [85-87]. Scanning spheres having $5 \AA$ radius have been reported to be suitable to explore steric effects in olefin polymerization [19]. Maps of the steric bulk, as shown in Figure $\mathrm{S} 1$ and Supporting Information, as well as the $\% V_{\text {bur }}$ values (total and separately for the four quadrants of the active pocket), as shown in Table 2, clearly indicate that the steric hindrance provided by the ancillary ligand is small and virtually identical for all complexes $\mathbf{R}_{\mathbf{1}} \mathbf{R}_{\mathbf{2}}$. This becomes even more evident when compared to a highly stereoselective catalyst of this class with ortho-1-adamantyl-para-methyl substituent pattern (AdMe) [41], providing additional evidence for steric effects at most marginally affecting relative comonomer affinity for this set of catalysts.

Table 2. Results of buried volume analysis for catalysts $\mathbf{R}_{\mathbf{1}} \mathbf{R}_{\mathbf{2}}$.

\begin{tabular}{ccccccc}
\hline \multirow{2}{*}{ Entry. } & \multirow{2}{*}{ Catalyst } & \multirow{2}{*}{ Total $\% \boldsymbol{V}_{\text {bur }}$} & \multicolumn{4}{c}{$\% \boldsymbol{V}_{\text {bur }}$ per Quadrant } \\
\cline { 4 - 7 } & & & $\mathbf{S W}$ & $\mathbf{N W}$ & $\mathbf{N E}$ & $\mathrm{SE}$ \\
\hline 1 & MeMe & 49.4 & 48.4 & 50.5 & 48.5 & 50.3 \\
2 & $\mathbf{M e C l}$ & 49.5 & 48.5 & 50.3 & 48.5 & 50.6 \\
3 & ClMe & 49.1 & 47.7 & 50.4 & 47.7 & 50.5 \\
4 & ClCl & 49.1 & 47.7 & 50.5 & 47.7 & 50.5 \\
5 & AdMe & 57.8 & 61.3 & 53.8 & 61.7 & 54.2 \\
\hline
\end{tabular}

Parameters: center of the sphere at the $\mathrm{Zr}$ atom; z-axis defined by $\mathrm{Zr}$ and the middle point between the two $\mathrm{Cl}$ atoms; $x z$ plane defined by $\mathrm{Zr}$ and one of the $\mathrm{Cl}$ atoms; radius of the sphere $=5 \AA$; hydrogen atoms included. $\mathrm{SW}=$ south-west; NW = north-west; $\mathrm{NE}=$ north-east; $\mathrm{SE}=$ south-east quadrants (see also Figure S2). AdMe provided for comparison. 


\subsubsection{Quantitative Kinetic Modeling of Reactivity Ratios for $\mathbf{R}_{\mathbf{1}} \mathbf{R}_{\mathbf{2}}$ in E/P Copolymerization}

Experimental and computational results indicate that differences in comonomer affinity are dictated predominantly by electronic effects in the present case study, yet, they cannot provide a rationale for this observation. Thus, the origins of comonomer affinities have been analyzed more in depth by attempting a direct modelling of the $r$-parameters of catalysts $\mathbf{R}_{\mathbf{1}} \mathbf{R}_{\mathbf{2}}$.

The drop of $r_{\mathrm{E}}$ from 60 (MeMe), as shown in Table 1, to $22(\mathrm{ClCl})$ in ethene/1-butene copolymerization is undoubtedly relevant in terms of polymer chemistry, signifying the passage from a very poor to a moderately good comonomer incorporator. However, such decrease corresponds only to a variation of $\Delta \Delta G^{\ddagger}$ (EB-EE) in the order of about $1 \mathrm{kcal} / \mathrm{mol}$, as shown in Table 1 , emphasizing that modeling these relative barriers is very challenging due to the required accuracy. For this reason, only the two extreme cases of $\mathbf{M e M e}$ and $\mathbf{C l C l}$ are considered here. From a computational point of view, propene is an appreciably more convenient model $\alpha$-olefin than 1-butene, especially when complex TSs have to be optimized. For better comparison between experiment and theory, $\mathbf{M e M e}$ and $\mathbf{C l C l}$ were re-tested in ethene/propene copolymerization, under reaction conditions analogous to those used for ethene/1-butene. The estimated $r_{\mathrm{E}}$ and $r_{\mathrm{P}}$ values and the corresponding $\Delta \Delta G^{\ddagger}$ are reported in Entries 1-2 of Table 3, showing similar differences in comonomer affinity for propene and 1-butene upon $\mathrm{Me} / \mathrm{Cl}$ exchange (compare Table 3 to Table 1 ).

Table 3. Experimental $r_{\mathrm{E}}$ and $r_{\mathrm{P}}$ for $\mathrm{MeMe}$ and $\mathrm{ClCl}$ in ethene/propene copolymerization and comparison between corresponding experimental and DFT calculated $\Delta \Delta G^{\ddagger}$.

\begin{tabular}{|c|c|c|c|c|c|c|}
\hline Entry & Catalyst & $r_{\mathrm{E}}$ & $\Delta \Delta G^{\ddagger}$ (EP-EE) & $r_{P}$ & $\Delta \Delta G^{\ddagger}$ (PE-PP) & $r_{\mathrm{E}} r_{\mathrm{P}}$ \\
\hline \multicolumn{7}{|c|}{ Experimental } \\
\hline 1 & MeMe & 41 & 2.2 & 0.03 & -2.1 & 1.2 \\
\hline 2 & $\mathrm{ClCl}$ & 8.7 & 1.3 & 0.19 & -1.0 & 1.7 \\
\hline \multicolumn{7}{|c|}{ DFT-INS only } \\
\hline 3 & MeMe & - & 1.5 [0.7] & - & $-1.6[-0.5]$ & \\
\hline 4 & $\mathrm{ClCl}$ & - & $1.3[0.0]$ & - & $-1.2[0.2]$ & \\
\hline \multicolumn{7}{|c|}{ DFT-INS and BBRA } \\
\hline 5 & MeMe & - & $1.5[0.7]$ & - & $-1.6[-0.5]$ & \\
\hline 6 & $\mathrm{ClCl}$ & - & $0.6[0.7]$ & - & $-1.2[0.2]$ & \\
\hline
\end{tabular}

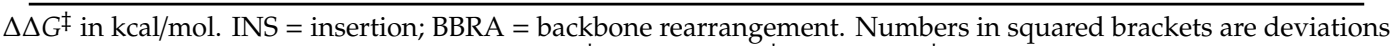
between experimental and DFT calculated $\Delta \Delta G^{\ddagger}$ (EP-EE) or $\Delta \Delta G^{\ddagger}$ (PE-PP). $\Delta \Delta G^{\ddagger}$ closer to zero are indicative of better comonomer incorporation.

Under the assumption that insertion is the rate-determining step for chain propagation in all cases, $\Delta \Delta G^{\ddagger}$ DFT indicate no significant difference in comonomer affinity for the two catalysts in terms of $r_{\mathrm{E}}$, and only a small one in terms of $r_{\mathrm{P}}$, as shown in Entries 3-4 of Table 3. The better comonomer incorporation capability of $\mathrm{ClCl}$ for $r_{\mathrm{P}}$ is, although slightly underestimated, reproduced. Experimental errors of $r_{\mathrm{C}}$ are generally higher than those of $r_{\mathrm{E}}$, due to difficulties in accurate determination $[26,37,39,88]$, and we will therefore focus on the discrepancy of experimental and DFT findings for $r_{\mathrm{E}}$ in the following.

As mentioned earlier, this discrepancy might be traced to a change in the rate-limiting step from insertion to a monomer capture-like process. For ansa-metallocenes, a backbone rearrangement (BBRA) corresponding to a breathing motion of backbone to accommodate the incoming olefin in the first coordination sphere of the metal has been identified, potentially affecting all propagation modes [39]. Here, we use the same nomenclature, although the open nature of catalysts $\mathbf{R}_{\mathbf{1}} \mathbf{R}_{\mathbf{2}}$ makes this structural rearrangement less obvious, as shown in the Supporting Information. Indeed, as there is no marked steric hurdle to monomer capture in catalysts $\mathbf{R}_{\mathbf{1}} \mathbf{R}_{\mathbf{2}}$, BBRA is generally a low energy process with respect to insertion for these catalysts. However, it always remains competitive and becomes kinetically relevant for very low insertion barriers, i.e., in ethene homopolymerization for $\mathbf{C l C l}$. Accounting for 
BBRA in the computational modelling therefore results in a lower $\Delta \Delta G^{\ddagger}$ (EP-EE) for $\mathrm{ClCl}(0.6 \mathrm{kcal} / \mathrm{mol})$ compared to competing insertion TSs $(1.3 \mathrm{kcal} / \mathrm{mol})$; all the other $\Delta \Delta G^{\ddagger}$ remain unchanged, as can be seen by Entries 3-4 vs. 5-6 in Table 3. The difference in experimental $r_{\mathrm{E}}$ for $\mathbf{M e M e}$ and $\mathbf{C l C l}$ is now perfectly reproduced, with a relatively small and constant deviation between experiments and theory of $0.7 \mathrm{kcal} / \mathrm{mol}$ that is quite satisfactory considering the complexity of the case study. While absolute rates are, both experimentally and computationally, often hard to determine accurately, relative rates are usually more reliable due to error compensation.

A closer inspection of the optimized geometries and DFT-calculated kinetic profiles provides a plausible interpretation for the different copolymerization performance of MeMe and ClCl. Relative Gibbs free energies for relevant TSs and reaction intermediates for ethene homo-propagation are summarized in Figure 4, highlighting the different metal-to-olefin distances found for the various geometries.

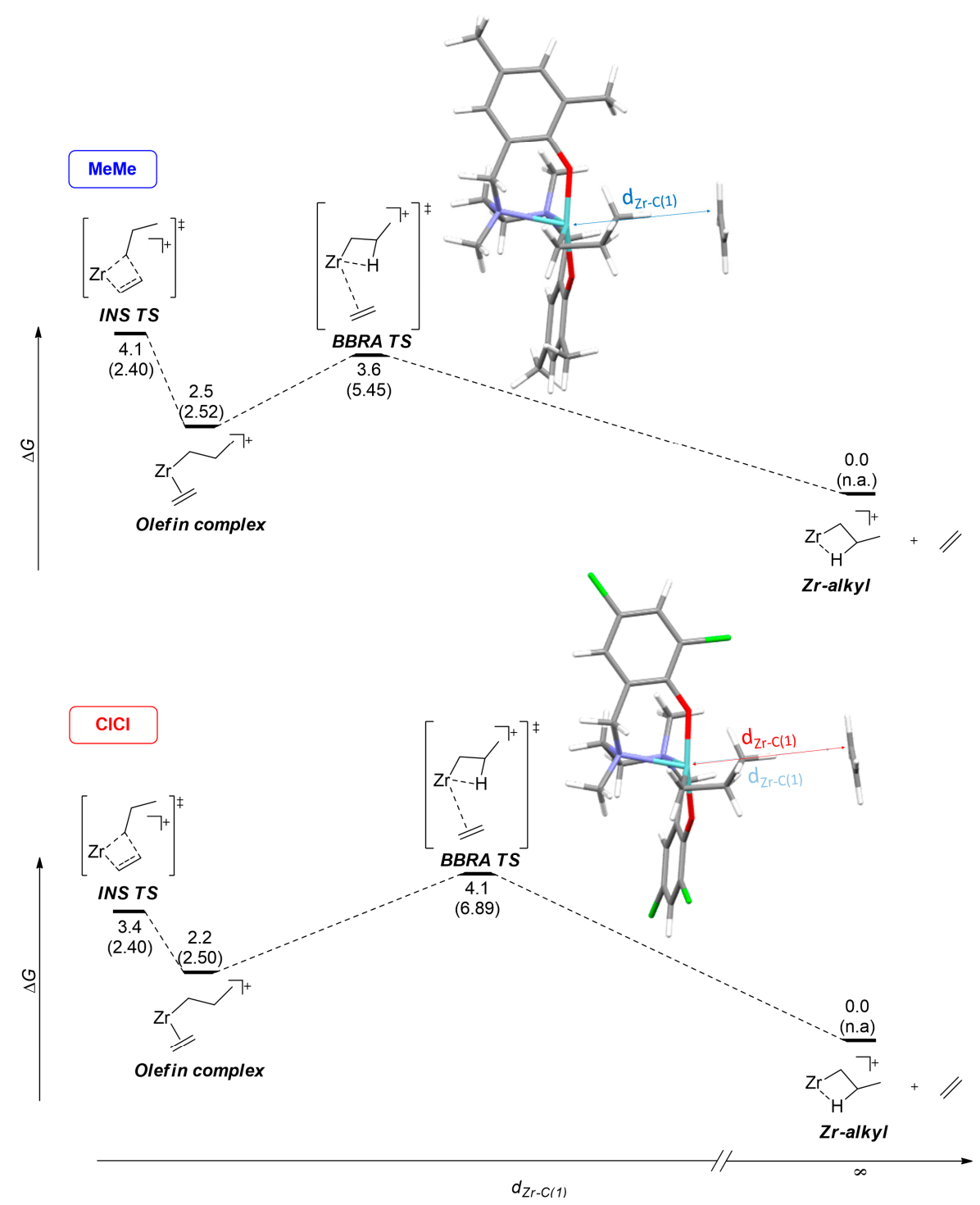

Figure 4. Energy profiles for ethene homopolymerization predicted by DFT for MeMe and ClCl. INS = insertion, BBRA = backbone rearrangement. Relative Gibbs free energy differences in $\mathrm{kcal} / \mathrm{mol}$; numbers in brackets: distances between the $\mathrm{Zr}$ and $\mathrm{C}(1)$ carbon of ethene in $\AA$ ( $\left.d_{\mathrm{Zr}-\mathrm{C}(1)}\right)$. $n \operatorname{Pr}$ group used as model for the polymeryl chain after ethene insertion (see Materials and Methods). 
$\mathrm{ClCl}$ binds ethene slightly more strongly than MeMe, likely due to the higher electrophilicity of its metal center (vide supra). The insertion barrier for $\mathrm{ClCl}$ is lower by $0.7 \mathrm{kcal} / \mathrm{mol}$ compared to MeMe, suggesting some electronic influence also in this respect [82]. Furthermore, BBRA activation barriers are found to be higher for $\mathbf{C l C l}$ than for MeMe. Higher associative and dissociative $\Delta G^{\ddagger}$ are expected for a more strongly coordinated olefin. In other words, replacing Me with $\mathrm{Cl}$ substituents appears to lower insertion but increase BBRA barriers, up to the point that the rate-limiting step can switch. Analogous considerations apply also to propene enchainment after ethene, as reported in the Supporting Information.

It is instructive to analyze the distances between the $\mathrm{Zr}$ center and the $\mathrm{C}(1)$ carbon of ethene $\left(d_{\mathrm{Zr}-\mathrm{C}(1)}\right)$. Insertion TSs appear to be very similar for the two catalysts, with a $d_{\mathrm{Zr}-\mathrm{C}(1)}$ close to $2.4 \AA$. This structural similarity is reflected by a similar $\Delta S^{\ddagger}$ INS for the two catalysts; differences in $\Delta G^{\ddagger}$ INS are mainly due to the $\Delta H^{\ddagger}$ INS term, as shown by Entries 1 vs. 3 in Table 4 . Conversely, $d_{\mathrm{Zr}-\mathrm{C}(1)}$ is about $1.5 \AA$ longer in the BBRA TS for $\mathrm{ClCl}$ than that for MeMe, diagnostic of a looser interaction between the metal and the incoming monomer. A lower $\Delta H^{\ddagger}$ BBRA is found for the former catalyst, as shown by Entries 2 vs. 4 in Table 4 , accordingly. Significantly lower $\Delta S^{\ddagger}$ BBRA than $\Delta S^{\ddagger}$ INS are estimated by DFT as a smaller fraction of the $2-1$ particle entropy loss for monomer capture has been paid at the BBRA rather than the insertion TS.

Table 4. Gibbs free energy, enthalpy, and entropy differences estimated by DFT for BBRA and insertion (INS) TS with respect to the $\beta$-agostic Zr-alkyl cation (in $\mathrm{kcal} / \mathrm{mol}$; see also Figure 4 ).

\begin{tabular}{cccccc}
\hline Entry & Catalyst & Process & $\Delta G^{\ddagger}$ & $\Delta \boldsymbol{H}^{\ddagger}$ & $\boldsymbol{\Delta} \boldsymbol{S}^{\ddagger}$ \\
\hline 1 & \multirow{2}{*}{$\mathbf{M e M e}$} & INS & 4.1 & -3.7 & 26 \\
2 & & BBRA & 3.6 & -0.7 & 14 \\
\hline 3 & \multirow{2}{*}{$\mathrm{ClCl}$} & INS & 3.4 & -4.6 & 27 \\
4 & & BBRA & 4.1 & -0.4 & 15 \\
\hline
\end{tabular}

Thus, increased electrophilicity of the active species might lead to lower insertion barriers, but not necessarily to lower propagation barriers, since BBRA might become the rate-determining step. In particular, in the case of $r_{\mathrm{E}}$ for $\mathrm{MeMe}$ and $\mathrm{ClCl}$, the replacement of Me with electron-withdrawing $\mathrm{Cl}$ substituents simultaneously lowers propene and raises ethene propagation barriers, as BBRA (and not insertion) becomes kinetically relevant for the latter. Both these effects contribute to increased comonomer incorporation capability.

\section{Conclusions}

The testing of [ONNO]-type $\mathrm{Zr}$ complexes in ethene/ $\alpha$-olefin copolymerization reveals that the replacement of electron-donating Me-substituents of the ancillary ligand with isosteric but electron-withdrawing $\mathrm{Cl}$ groups, leads to a significant increase of comonomer affinity in the polymer chain. This indicates that, for this catalyst set, the electronic properties of the active species are the main parameter determining comonomer affinities. This is supported by DFT studies exploring electronic and steric features of the ancillary ligands.

Quantitative kinetic analysis of propagation rates by DFT shows that barriers for olefin insertion are lowered when electron-withdrawing substituents are installed on the catalyst backbone, while those for capture/BBRA increase. Reactivity ratios in copolymerization are therefore determined by the subtle balance between insertion and BBRA kinetics and cooperative effects can simultaneously decrease comonomer propagation barriers but increase those for ethene, when BBRA becomes rate limiting.

Electronic tuning effects in olefin (co)polymerization are still ill understood and the insights presented here allow for the first time a clear separation of steric and electronic effects. The ultimate goal in the design of catalysts for olefin copolymerization is typically to develop systems that prefer $\alpha$-olefins over the generally more reactive ethene, and to finely tune this preference to access advanced materials for specific applications. The insights presented in this paper provide the means of 
understanding of electronic effects in copolymerization, which should prove useful for the design of new copolymerization catalysts.

Supplementary Materials: The following are available online at http://www.mdpi.com/2227-9717/7/6/384/s1, Table S1: Polymerization results, Figure S1: Buried volume analysis, Table S2: Electronic charges, Figure S2: Calculated reaction profiles for propene enchainment after ethene, Table S3: Final energies, entropy, and enthalpy corrections in Hartree, Full Gaussian citation.

Author Contributions: Conceptualization, R.C., V.B., C.E.; methodology, R.C., V.B., C.E.; formal analysis, R.C., F.Z., A.C.; investigation, F.Z., R.C., C.E.; resources, V.B.; writing—original draft preparation, F.Z.; writing-review and editing, R.C., A.C., P.H.M.B., V.B., C.E.; visualization, F.Z.; supervision, R.C., P.H.M.B., V.B.

Funding: This research received no external funding.

Conflicts of Interest: The authors declare no conflict of interest.

\section{References}

1. Stürzel, M.; Mihan, S.; Mülhaupt, R. From Multisite Polymerization Catalysis to Sustainable Materials and All-Polyolefin Composites. Chem. Rev. 2016, 116, 1398-1433. [CrossRef] [PubMed]

2. Sauter, D.; Taoufik, M.; Boisson, C. Polyolefins, a Success Story. Polymers 2017, 9, 185. [CrossRef] [PubMed]

3. Simpson, D.M.; Vaugham, G.A. Encyclopedia of Polymer Science and Technology, 4th ed.; John Wiley \& Sons, Inc.: Hoboken, NJ, USA, 2014; Volume 5.

4. Bensason, S.; Minick, J.; Moet, A.; Chum, S.; Hiltner, A.; Baer, E. Classification of homogeneous ethylene-octene copolymers based on comonomer content. J. Polym. Sci. Part B Polym. Phys. 1996, 34, 1301-1315. [CrossRef]

5. Xu, X.; Xu, J.; Feng, L.; Chen, W. Effect of short chain-branching distribution on crystallinity and modulus of metallocene-based ethylene-butene copolymers. J. Appl. Polym. Sci. 2000, 77, 1709-1715. [CrossRef]

6. Burfield, D.R. Correlation between crystallinity and ethylene content in LLDPE and related ethylene copolymers: Demonstration of the applicability of a simple empirical relationship. Macromolecules 1987, 20, 3020-3023. [CrossRef]

7. Baier, M.C.; Zuideveld, M.A.; Mecking, S. Post-Metallocenes in the Industrial Production of Polyolefins. Angew. Chem. Int. Ed. 2014, 53, 9722-9744. [CrossRef] [PubMed]

8. Klosin, J.; Fontaine, P.P.; Figueroa, R. Development of Group IV Molecular Catalysts for High Temperature Ethylene- $\alpha$-Olefin Copolymerization Reactions. Acc. Chem. Res. 2015, 48, 2004-2016. [CrossRef] [PubMed]

9. Kaminsky, W. The discovery of metallocene catalysts and their present state of the art. J. Polym. Sci. Part A Polym. Chem. 2004, 42, 3911-3921. [CrossRef]

10. Ehm, C.; Zaccaria, F.; Cipullo, R. From Mechanistic Investigation to Quantitative Prediction. In Computational Quantum Chemistry; Soroush, M., Ed.; Elsevier: Amsterdam, The Netherlands, 2019; pp. 287-326.

11. Hooper, M.S.; Michalak, A. Computational Modeling of Polymerization Catalysts. In Handbook of Transition Metal Polymerization Catalysts; Wiley-VCH: Weinheim, Germany, 2018.

12. Rappé, A.K.; Skiff, W.M.; Casewit, C.J. Modeling Metal-Catalyzed Olefin Polymerization. Chem. Rev. 2000, 100, 1435-1456. [CrossRef]

13. Corradini, P.; Guerra, G.; Cavallo, L. Do New Century Catalysts Unravel the Mechanism of Stereocontrol of Old Ziegler-Natta Catalysts? Acc. Chem. Res. 2004, 37, 231-241. [CrossRef]

14. Coates, G.W. Precise Control of Polyolefin Stereochemistry Using Single-Site Metal Catalysts. Chem. Rev. 2000, 100, 1223-1252. [CrossRef] [PubMed]

15. Resconi, L.; Cavallo, L.; Fait, A.; Piemontesi, F. Selectivity in Propene Polymerization with Metallocene Catalysts. Chem. Rev. 2000, 100, 1253-1346. [CrossRef]

16. Busico, V.; Cipullo, R. Microstructure of polypropylene. Prog. Polym. Sci. 2001, 26, 443-533. [CrossRef]

17. Talarico, G.; Budzelaar, P.H.M. Analysis of Stereochemistry Control in Homogeneous Olefin Polymerization Catalysis. Organometallics 2014, 33, 5974-5982. [CrossRef]

18. Castro, L.; Therukauff, G.; Vantomme, A.; Welle, A.; Haspeslagh, L.; Brusson, J.M.; Maron, L.; Carpentier, J.F.; Kirillov, E. A Theoretical Outlook on the Stereoselectivity Origins of Isoselective Zirconocene Propylene Polymerization Catalysts. Chem. Eur. J. 2018, 24, 10784-10792. [CrossRef] [PubMed]

19. Ehm, C.; Vittoria, A.; Goryunov, G.P.; Kulyabin, P.S.; Budzelaar, P.H.M.; Voskoboynikov, A.Z.; Busico, V.; Uborsky, D.V.; Cipullo, R. Connection of Stereoselectivity, Regioselectivity, and Molecular Weight Capability in rac- $\mathrm{R}_{2}{ }_{2} \mathrm{Si}\left(2-\mathrm{Me}-4-\mathrm{R}\right.$-indenyl) ${ }_{2} \mathrm{ZrCl}_{2}$ Type Catalysts. Macromolecules 2018, 51, 8073-8083. [CrossRef] 
20. Talarico, G.; Budzelaar, P.H.M. Ligand Coordination Driven by Monomer and Polymer Chain: The Intriguing Case of Salalen-Ti Catalyst for Propene Polymerization. Macromolecules 2017, 50, 5332-5336. [CrossRef]

21. Domski, G.J.; Eagan, J.M.; De Rosa, C.; Di Girolamo, R.; LaPointe, A.M.; Lobkovsky, E.B.; Talarico, G.; Coates, G.W. Combined Experimental and Theoretical Approach for Living and Isoselective Propylene Polymerization. ACS Catal. 2017, 7, 6930-6937. [CrossRef]

22. Milano, G.; Cavallo, L.; Guerra, G. Site Chirality as a Messenger in Chain-End Stereocontrolled Propene Polymerization. J. Am. Chem. Soc. 2002, 124, 13368-13369. [CrossRef]

23. Brintzinger, H.H.; Fischer, D.; Mülhaupt, R.; Rieger, B.; Waymouth, R.M. Stereospecific Olefin Polymerization with Chiral Metallocene Catalysts. Angew. Chem. Int. Ed. Eng. 1995, 34, 1143-1170. [CrossRef]

24. Kakugo, M.; Naito, Y.; Mizunuma, K.; Miyatake, T. Carbon-13 NMR determination of monomer sequence distribution in ethylene-propylene copolymers prepared with $\delta$-titanium trichloride-diethylaluminum chloride. Macromolecules 1982, 15, 1150-1152. [CrossRef]

25. Randall, J.C. A review of high resolution liquind ${ }^{13}$ carbon nuclear magnetic resonance characterizations of ethylene-based polymers. J. Macromol. Sci. Part C 1989, 29, 201-317. [CrossRef]

26. Busico, V.; Cipullo, R.; Segre, A.L. Advances in the ${ }^{13} \mathrm{C}$ NMR characterization of ethene/propene copolymers, 1. Macromol. Chem. Phys. 2002, 203, 1403-1412. [CrossRef]

27. Dankova, M.; Waymouth, R.M. High Comonomer Selectivity in Ethylene/Hexene Copolymerization by Unbridged Indenyl Metallocenes. Macromolecules 2003, 36, 3815-3820. [CrossRef]

28. Reybuck, S.E.; Meyer, A.; Waymouth, R.M. Copolymerization Behavior of Unbridged Indenyl Metallocenes: Substituent Effects on the Degree of Comonomer Incorporation. Macromolecules 2002, 35, 637-643. [CrossRef]

29. Kunz, K.; Erker, G.; Kehr, G.; Fröhlich, R.; Jacobsen, H.; Berke, H.; Blacque, O. Formation of Cyclodimeric $\left(\mathrm{sp}^{2}-\mathrm{C}_{1}\right.$ )-Bridged $\mathrm{Cp}$-Oxido (“ $\mathrm{CpC}_{1} \mathrm{O}^{\prime \prime} \mathrm{M}^{\mathrm{IV}} \mathrm{X}_{2}$ ) Group 4 Metal Ziegler-Natta Catalyst SystemsHow Important Is the "Constrained Geometry" Effect? J. Am. Chem. Soc. 2002, 124, 3316-3326. [CrossRef] [PubMed]

30. Möhring, P.C.; Coville, N.J. The influence of cyclopentadienyl ring substituent steric and electronic effects on the ethylene- $\alpha$-olefin copolymerisation behaviour of $(\mathrm{CpR})_{2} \mathrm{ZrCl}_{2}$ ethylalumoxane catalysts. J. Mol. Catal. A Chem. 1995, 96, 181-195. [CrossRef]

31. Thornberry, M.P.; Reynolds, N.T.; Deck, P.A.; Fronczek, F.R.; Rheingold, A.L.; Liable-Sands, L.M. Synthesis, Structure, and Olefin Polymerization Catalytic Behavior of Aryl-Substituted Zirconocene Dichlorides. Organometallics 2004, 23, 1333-1339. [CrossRef]

32. Lehmus, P.; Kokko, E.; Härkki, O.; Leino, R.; Luttikhedde, H.J.G.; Näsman, J.H.; Seppälä, J.V. Homo- and Copolymerization of Ethylene and $\alpha$-Olefins over 1- and 2-Siloxy-Substituted Ethylenebis(indenyl)zirconium and Ethylenebis(tetrahydroindenyl)zirconium Dichlorides. Macromolecules 1999, 32, 3547-3552. [CrossRef]

33. Zaccaria, F.; Ehm, C.; Budzelaar, P.H.M.; Busico, V. Accurate Prediction of Copolymerization Statistics in Molecular Olefin Polymerization Catalysis: The Role of Entropic, Electronic, and Steric Effects in Catalyst Comonomer Affinity. ACS Catal. 2017, 7, 1512-1519. [CrossRef]

34. Yano, A.; Hasegawa, S.; Kaneko, T.; Sone, M.; Sato, M.; Akimoto, A. Ethylene/1-hexene copolymerization with $\mathrm{Ph}_{2} \mathrm{C}(\mathrm{Cp})(\mathrm{Flu}) \mathrm{ZrCl}_{2}$ derivatives: Correlation between ligand structure and copolymerization behavior at high temperature. Macromol. Chem. Phys. 1999, 200, 1542-1553. [CrossRef]

35. Gassman, P.G.; Mickelson, J.W.; Sowa, J.R. 1,2,3,4-Tetramethyl-5-(trifluoromethyl)cyclopentadienide: A unique ligand with the steric properties of pentamethylcyclopentadienide and the electronic properties of cyclopentadienide. J. Am. Chem. Soc. 1992, 114, 6942-6944. [CrossRef]

36. Nsiri, H.; Belaid, I.; Larini, P.; Thuilliez, J.; Boisson, C.; Perrin, L. Ethylene-Butadiene Copolymerization by Neodymocene Complexes: A Ligand Structure/Activity/Polymer Microstructure Relationship Based on DFT Calculations. ACS Catal. 2016, 6, 1028-1036. [CrossRef]

37. Friederichs, N.; Wang, B.; Budzelaar, P.H.M.; Coussens, B.B. A combined experimental—molecular modeling approach for ethene-propene copolymerization with $C_{2}$-symmetric metallocenes. J. Mol. Catal. A Chem. 2005, 242, 91-104. [CrossRef]

38. Laine, A.; Coussens, B.B.; Hirvi, J.T.; Berthoud, A.; Friederichs, N.; Severn, J.R.; Linnolahti, M. Effect of Ligand Structure on Olefin Polymerization by a Metallocene/Borate Catalyst: A Computational Study. Organometallics 2015, 34, 2415-2421. [CrossRef]

39. Zaccaria, F.; Cipullo, R.; Budzelaar, P.H.M.; Busico, V.; Ehm, C. Backbone rearrangement during olefin capture as the rate limiting step in molecular olefin polymerization catalysis and its effect on comonomer affinity. J. Polym. Sci. Part A Polym. Chem. 2017, 55, 2807-2814. [CrossRef] 
40. Tshuva, E.Y.; Goldberg, I.; Kol, M. Isospecific Living Polymerization of 1-Hexene by a Readily Available Nonmetallocene $C_{2}$-Symmetrical Zirconium Catalyst. J. Am. Chem. Soc. 2000, 122, 10706-10707. [CrossRef]

41. Busico, V.; Cipullo, R.; Pellecchia, R.; Ronca, S.; Roviello, G.; Talarico, G. Design of stereoselective Ziegler-Natta propene polymerization catalysts. Proc. Natl. Acad. Sci. USA 2006, 103, 15321-15326. [CrossRef]

42. Ciancaleoni, G.; Fraldi, N.; Cipullo, R.; Busico, V.; Macchioni, A.; Budzelaar, P.H.M. Structure/Properties Relationship for Bis(phenoxyamine)Zr(IV)-Based Olefin Polymerization Catalysts: A Simple DFT Model To Predict Catalytic Activity. Macromolecules 2012, 45, 4046-4053. [CrossRef]

43. Ciancaleoni, G.; Fraldi, N.; Budzelaar, P.H.M.; Busico, V.; Cipullo, R.; Macchioni, A. Structure-Activity Relationship in Olefin Polymerization Catalysis: Is Entropy the Key? J. Am. Chem. Soc. 2010, 132, 13651-13653. [CrossRef]

44. Busico, V.; Cipullo, R.; Friederichs, N.; Ronca, S.; Talarico, G.; Togrou, M.; Wang, B. Block Copolymers of Highly Isotactic Polypropylene via Controlled Ziegler-Natta Polymerization. Macromolecules 2004, 37, 8201-8203. [CrossRef]

45. Busico, V.; Cipullo, R.; Ronca, S.; Budzelaar, P.H.M. Mimicking Ziegler-Natta Catalysts in Homogeneous Phase, 1. $\mathrm{C}_{2}$-Symmetric Octahedral $\mathrm{Zr}(\mathrm{IV})$ Complexes with Tetradentate [ONNO]-Type Ligands. Macromol. Rapid Commun. 2001, 22, 1405-1410. [CrossRef]

46. Segal, S.; Goldberg, I.; Kol, M. Zirconium and Titanium Diamine Bis(phenolate) Catalysts for $\alpha$-Olefin Polymerization: From Atactic Oligo(1-hexene) to Ultrahigh-Molecular-Weight Isotactic Poly(1-hexene). Organometallics 2005, 24, 200-202. [CrossRef]

47. Cohen, A.; Kopilov, J.; Goldberg, I.; Kol, M. C1-Symmetric Zirconium Complexes of [ONNO']-Type Salan Ligands: Accurate Control of Catalyst Activity, Isospecificity, and Molecular Weight in 1-Hexene Polymerization. Organometallics 2009, 28, 1391-1405. [CrossRef]

48. Busico, V.; Cipullo, R.; Romanelli, V.; Ronca, S.; Togrou, M. Reactivity of Secondary Metal-Alkyls in Catalytic Propene Polymerization: How Dormant Are “Dormant Chains”? J. Am. Chem. Soc. 2005, 127, 1608-1609. [CrossRef]

49. Busico, V.; Cipullo, R.; Friederichs, N.; Ronca, S.; Togrou, M. The First Molecularly Characterized Isotactic Polypropylene-block-polyethylene Obtained via "Quasi-Living" Insertion Polymerization. Macromolecules 2003, 36, 3806-3808. [CrossRef]

50. Preston, A.Z.; Kim, J.; Medvedev, G.A.; Delgass, W.N.; Caruthers, J.M.; Abu-Omar, M.M. Steric and Solvation Effects on Polymerization Kinetics, Dormancy, and Tacticity of Zr-Salan Catalysts. Organometallics 2017, 36, 2237-2244. [CrossRef]

51. Ciancaleoni, G.; Fraldi, N.; Budzelaar, P.H.M.; Busico, V.; Macchioni, A. Activation of a bis(phenoxy-amine) precatalyst for olefin polymerisation: First evidence for an outer sphere ion pair with the methylborate counterion. Dalton Trans. 2009, 8824-8827. [CrossRef]

52. Busico, V.; Cipullo, R.; Cutillo, F.; Friederichs, N.; Ronca, S.; Wang, B. Improving the Performance of Methylalumoxane: A Facile and Efficient Method to Trap "Free" Trimethylaluminum. J. Am. Chem. Soc. 2003, 125, 12402-12403. [CrossRef]

53. Zaccaria, F.; Zuccaccia, C.; Cipullo, R.; Budzelaar, P.H.M.; Macchioni, A.; Busico, V.; Ehm, C. BHT-Modified MAO: Cage Size Estimation, Chemical Counting of Strongly Acidic Al Sites, and Activation of a Ti-Phosphinimide Precatalyst. ACS Catal. 2019, 9, 2996-3010. [CrossRef]

54. Kissin, Y. Isospecific Polymerization of Olefins: With Heterogeneous Ziegler-Natta Catalysts; Springer: New York, NY, USA, 1985.

55. Hamm, G.E. In "Copolymerization"; Hamm, G.E., Ed.; Wiley-Interscience: New York, NY, USA, 1964; Chapter I.

56. Ehm, C.; Budzelaar, P.H.M.; Busico, V. Calculating accurate barriers for olefin insertion and related reactions. J. Organomet. Chem. 2015, 775, 39-49. [CrossRef]

57. Gaussian 09, Revision B.1; Gaussian, Inc.: Wallingford, CT, USA, 2009; for the full citation see the Supporting Information.

58. Baker, J. PQS, version 2.4; Parallel Quantum Solutions: Fayetteville, AR, USA, 2001.

59. Baker, J. An algorithm for the location of transition states. J. Comput. Chem. 1986, 7, 385-395. [CrossRef]

60. Budzelaar, P.H.M. Geometry optimization using generalized, chemically meaningful constraints. J. Comput. Chem. 2007, 28, 2226-2236. [CrossRef] 
61. Tao, J.; Perdew, J.P.; Staroverov, V.N.; Scuseria, G.E. Climbing the Density Functional Ladder: Nonempirical Meta \char21\{\}Generalized Gradient Approximation Designed for Molecules and Solids. Phys. Rev. Lett. 2003, 91, 146401. [CrossRef] [PubMed]

62. Peterson, K.A.; Figgen, D.; Dolg, M.; Stoll, H. Energy-consistent relativistic pseudopotentials and correlation consistent basis sets for the 4d elements Y-Pd. J. Chem. Phys. 2007, 126, 142101. [CrossRef] [PubMed]

63. Schuchardt, K.L.; Didier, B.T.; Elsethagen, T.; Sun, L.; Gurumoorthi, V.; Chase, J.; Li, J.; Windus, T.L. Basis Set Exchange: A Community Database for Computational Sciences. J. Chem. Inf. Model. 2007, 47, 1045-1052. [CrossRef] [PubMed]

64. Whitten, J.L. Coulombic potential energy integrals and approximations. J. Chem. Phys. 1973, 58, 4496-4501. [CrossRef]

65. Baerends, E.J.; Ellis, D.E.; Ros, P. Self-consistent molecular Hartree-Fock-Slater calculations I. The computational procedure. Chem. Phys. 1973, 2, 41-51. [CrossRef]

66. Feyereisen, M.; Fitzgerald, G.; Komornicki, A. Use of approximate integrals in ab initio theory. An application in MP2 energy calculations. Chem. Phys. Lett. 1993, 208, 359-363. [CrossRef]

67. Vahtras, O.; Almlöf, J.; Feyereisen, M.W. Integral approximations for LCAO-SCF calculations. Chem. Phys. Lett. 1993, 213, 514-518. [CrossRef]

68. Flisak, Z.; Ziegler, T. "Dormant" secondary metal-alkyl complexes are not omnipresent. Proc. Natl. Acad. Sci. USA 2006, 103, 15338-15342. [CrossRef] [PubMed]

69. Foster, J.P.; Weinhold, F. Natural hybrid orbitals. J. Am. Chem. Soc. 1980, 102, 7211-7218. [CrossRef]

70. Zhao, Y.; Truhlar, D.G. The M06 suite of density functionals for main group thermochemistry, thermochemical kinetics, noncovalent interactions, excited states, and transition elements: Two new functionals and systematic testing of four M06-class functionals and 12 other function. Theor. Chem. Acc. 2008, 120, 215-241. [CrossRef]

71. Tobisch, S.; Ziegler, T. Catalytic Oligomerization of Ethylene to Higher Linear $\alpha$-Olefins Promoted by the Cationic Group 4 [( $\eta^{5}-\mathrm{Cp}-\left(\mathrm{CMe}_{2}\right.$-bridge $\left.)-\mathrm{Ph}\right) \mathrm{M}^{\mathrm{II}}$ (ethylene $\left.)_{2}\right]^{+}(\mathrm{M}=\mathrm{Ti}, \mathrm{Zr}$, Hf) Active Catalysts: A Density Functional Investigation of the Influence of the Metal on the Catalyt. J. Am. Chem. Soc. 2004, 126, 9059-9071. [CrossRef] [PubMed]

72. Crabtree, R.H. Deactivation in Homogeneous Transition Metal Catalysis: Causes, Avoidance, and Cure. Chem. Rev. 2015, 115, 127-150. [CrossRef] [PubMed]

73. Cipullo, R.; Melone, P.; Yu, Y.; Iannone, D.; Busico, V. Olefin polymerisation catalysts: When perfection is not enough. Dalton Trans. 2015, 44, 12304-12311. [CrossRef] [PubMed]

74. Zaccaria, F.; Ehm, C.; Budzelaar, P.H.M.; Busico, V.; Cipullo, R. Catalyst Mileage in Olefin Polymerization: The Peculiar Role of Toluene. Organometallics 2018, 37, 2872-2879. [CrossRef]

75. Desert, X.; Carpentier, J.-F.; Kirillov, E. Quantification of active sites in single-site group 4 metal olefin polymerization catalysis. Coord. Chem. Rev. 2019, 386, 50-68. [CrossRef]

76. Alameddin, N.G.; Ryan, M.F.; Eyler, J.R.; Siedle, A.R.; Richardson, D.E. Intrinsic Ancillary Ligand Effects in Cationic Zirconium Polymerization Catalysts: Reactions of $\left[\mathrm{L}_{2} \mathrm{ZrCH}_{3}\right]^{+}$Cations with $\mathrm{H}_{2}$ and $\mathrm{C}_{2} \mathrm{H}_{4}$. Organometallics 1995, 14, 5005-5007. [CrossRef]

77. Richardson, D.E.; Alameddin, N.G.; Ryan, M.F.; Hayes, T.; Eyler, J.R.; Siedle, A.R. Intrinsic Ancillary Ligand Effects in Cationic Zirconium Polymerization Catalysts: Gas-Phase Reactions of $\left[\mathrm{L}_{2} \mathrm{ZrCH}_{3}\right]^{+}$Cations with Alkenes. J. Am. Chem. Soc. 1996, 118, 11244-11253. [CrossRef]

78. Macchioni, A. Ion Pairing in Transition-Metal Organometallic Chemistry. Chem. Rev. 2005, 105, $2039-2074$. [CrossRef] [PubMed]

79. Resconi, L.; Camurati, I.; Sudmeijer, O. Chain transfer reactions in propylene polymerization with zirconocene catalysts. Top. Catal. 1999, 7, 145-163. [CrossRef]

80. Ehm, C.; Antinucci, G.; Budzelaar, P.H.M.; Busico, V. Catalyst activation and the dimerization energy of alkylaluminium compounds. J. Organomet. Chem. 2014, 772-773, 161-171. [CrossRef]

81. Ehm, C.; Budzelaar, P.H.M.; Busico, V. Metal-carbon bond strengths under polymerization conditions: 2,1-insertion as a catalyst stress test. J. Catal. 2017, 351, 146-152. [CrossRef]

82. Ehm, C.; Budzelaar, P.H.M.; Busico, V. Tuning the Relative Energies of Propagation and Chain Termination Barriers in Polyolefin Catalysis through Electronic and Steric Effects. Eur. J. Inorg. Chem. 2017, 3343-3349. [CrossRef] 
83. Ishii, A.; Ikuma, K.; Nakata, N.; Nakamura, K.; Kuribayashi, H.; Takaoki, K. Zirconium and Hafnium Complexes with Cycloheptane- or Cyclononane-Fused [OSSO]-Type Bis(phenolato) Ligands: Synthesis, Structure, and Highly Active 1-Hexene Polymerization and Ring-Size Effects of Fused Cycloalkanes on the Activity. Organometallics 2017, 36, 3954-3966. [CrossRef]

84. Liptak, M.D.; Gross, K.C.; Seybold, P.G.; Feldgus, S.; Shields, G.C. Absolute pKa Determinations for Substituted Phenols. J. Am. Chem. Soc. 2002, 124, 6421-6427. [CrossRef]

85. Falivene, L.; Credendino, R.; Poater, A.; Petta, A.; Serra, L.; Oliva, R.; Scarano, V.; Cavallo, L. SambVca 2. A Web Tool for Analyzing Catalytic Pockets with Topographic Steric Maps. Organometallics 2016, 35, 2286-2293. [CrossRef]

86. Clavier, H.; Correa, A.; Cavallo, L.; Escudero-Adán, E.C.; Benet-Buchholz, J.; Slawin, A.M.Z.; Nolan, S.P. $[\mathrm{Pd}(\mathrm{NHC})($ allyl)Cl] Complexes: Synthesis and Determination of the NHC Percent Buried Volume (\%Vbur) Steric Parameter. Eur. J. Inorg. Chem. 2009, 2009, 1767-1773. [CrossRef]

87. Poater, A.; Cosenza, B.; Correa, A.; Giudice, S.; Ragone, F.; Scarano, V.; Cavallo, L. SambVca: A Web Application for the Calculation of the Buried Volume of N-Heterocyclic Carbene Ligands. Eur. J. Inorg. Chem. 2009, 2009, 1759-1766. [CrossRef]

88. Galimberti, M.; Mascellani, N.; Piemontesi, F.; Camurati, I. Random ethene/propene copolymerization from a catalyst system based on a "constrained geometry" half-sandwich complex. Macromol. Rapid Commun. 1999, 20, 214-218. [CrossRef]

(C) 2019 by the authors. Licensee MDPI, Basel, Switzerland. This article is an open access article distributed under the terms and conditions of the Creative Commons Attribution (CC BY) license (http://creativecommons.org/licenses/by/4.0/). 